Abstract 1110 Table 3 Immunosuppressive treatment in the CARRA CSLE Registry Cohort ( $\mathrm{N}=671)$

\begin{tabular}{|l|c|c|}
\hline Medication & $\begin{array}{c}\text { Ever Prescribed } \\
\text { N (\%) }\end{array}$ & $\begin{array}{c}\text { Currently prescribed } \\
\text { N (\%) }\end{array}$ \\
\hline Steroids & $614(83.7)$ & $308(42)$ \\
\hline Oral & $569(77.5)$ & $305(41.6)$ \\
\hline Intravenous & $319(43.5)$ & $15(2)$ \\
\hline Hydroxychloroquine & $631(94)$ & $598(89.1)$ \\
\hline Mycophenolate Mofetil & $373(55.6)$ & $295(44)$ \\
\hline Cyclophosphamide & $97(14.5)$ & $22(3.3)$ \\
\hline Azathioprine & $131(19.5)$ & $81(12.1)$ \\
\hline Rituximab & $131(16.7)$ & $28(4.1)$ \\
\hline Belimumab & $32(4.9)$ & $28(4.2)$ \\
\hline Other $^{1}$ & $113(16.8)$ & $60(8.9)$ \\
\hline
\end{tabular}

modifying anti-rheumatic drugs such as Leflunomide and Methotrexate. $84 \%$ of patients were prescribed either oral or intravenous glucocorticoids during their disease course (table 3).

Conclusions The CARRA Registry has enrolled a racially and ethnically diverse cohort of cSLE patients in the early course of their disease. These participants exhibit moderate disease activity and although the use of hydroxychloroquine in this cohort is high, a significant proportion of patients are utilizing glucocorticoids at the last study visit. We anticipate enrolling a minimum of 1000 participants with more than ten years of follow-up. This cohort, which is one of the Centers for Disease Control (CDC) funded SLE registries, provides a unique opportunity to describe the natural history, treatments, and outcomes in patients with cSLE.

\section{INCREASING ACCESS AND QUALITY OF CARE FOR INDIVIDUALS FROM UNDERREPRESENTED COMMUNITIES LIVING WITH LUPUS: INSIGHTS FROM QUALITATIVE INTERVIEWS WITH PATIENTS AND PHYSICIANS}

1,2Saira Z Sheikh*, ${ }^{3}$ Maria L Naylor, ${ }^{3}$ Lasair O'Callaghan, ${ }^{3}$ Lina Sladkeviciute, ${ }^{3}$ Janine GaihaRohrbach, ${ }^{3}$ Cherie Butts. 'University of North Carolina at Chapel Hill, Thurston Arthritis Research Center, Chapel Hill, NC, USA; ${ }^{2}$ University of North Carolina at Chapel Hill School of Medicine, Department of Medicine, Division of Rheumatology, Allergy and Immunology, Chapel Hill, NC, USA; ${ }^{3}$ Biogen, Cambridge, MA, USA

\subsection{6/lupus-2021-lupus21century.54}

Background Lupus disproportionately affects Black/African American (AA) and Latino/a patients, yet these underrepresented racial/ethnic minority populations often face challenges with accessing quality care. ${ }^{1,2}$ We aimed to explore patients'

\section{Abstract 1111 Table 1 Demographics of Patient and Physician Participants}

\begin{tabular}{lll}
\hline Characteristic, $\mathrm{n}(\%)$ & $\begin{array}{l}\text { Patients }^{\mathrm{a}} \\
(\mathrm{n}=33)\end{array}$ & $\begin{array}{l}\text { Physicians }^{\mathrm{a}} \\
(\mathbf{n}=20)\end{array}$ \\
\hline Patient age & & \\
$18-35$ years & $4(12)$ & NA \\
$36-65$ years & $26(79)$ & NA \\
$66+$ years & $3(9)$ & NA \\
Female & $29(88)$ & NA
\end{tabular}

\begin{tabular}{|c|c|c|}
\hline \multicolumn{3}{|l|}{ Race/Ethnicity } \\
\hline Black/African American & $16(48)$ & $2(10)$ \\
\hline Latino/a & $10(30)$ & 0 \\
\hline Asian/Pacific Islander & $5(15)$ & $4(20)$ \\
\hline Native American & $2(6)$ & $1(5)$ \\
\hline White/Caucasian & 0 & $12(60)$ \\
\hline Prefer not to disclose & 0 & $1(5)$ \\
\hline \multicolumn{3}{|l|}{ Region } \\
\hline Northeast & $11(33)$ & $8(40)$ \\
\hline Midwest & $5(15)$ & $1(5)$ \\
\hline South & $12(36)$ & $8(40)$ \\
\hline West & $5(15)$ & $3(15)$ \\
\hline \multicolumn{3}{|l|}{ Education level } \\
\hline Some high school or less ${ }^{b}$ & $2(6)$ & 0 \\
\hline Some college & $8(24)$ & 0 \\
\hline Graduated college/technical school & $17(52)$ & 0 \\
\hline Postgraduate degree & $6(18)$ & $20(100)$ \\
\hline \multicolumn{3}{|l|}{ Employment status } \\
\hline Full time & $11(33)$ & NA \\
\hline Part time & $4(12)$ & NA \\
\hline Other ${ }^{c}$ & $18(55)$ & NA \\
\hline \multicolumn{3}{|l|}{ Type of lupus } \\
\hline SLE & $23(70)$ & NA \\
\hline CLE & $4(12)$ & NA \\
\hline Other $^{d}$ & $6(18)$ & NA \\
\hline \multicolumn{3}{|l|}{ Severity of lupus } \\
\hline Mild & $4(12)$ & NA \\
\hline Moderate & $23(70)$ & NA \\
\hline Severe & $6(18)$ & NA \\
\hline Physician specialty & NA & \\
\hline Rheumatology & NA & $11(55)$ \\
\hline Dermatology & NA & $9(45)$ \\
\hline \multicolumn{3}{|l|}{ Investigator vs referring physician } \\
\hline Referring physician & NA & $14(70)$ \\
\hline Investigator & NA & $6(30)$ \\
\hline \multicolumn{3}{|l|}{ Years experience post-residency } \\
\hline $5-19$ years & NA & $13(65)$ \\
\hline $20+$ years & NA & $7(35)$ \\
\hline \multicolumn{3}{|l|}{ Physician practice: patient race } \\
\hline $\begin{array}{l}\text { Majority Black or African American (> } 50 \% \text { of } \\
\text { patients) }\end{array}$ & NA & $7(35)$ \\
\hline Majority White/Caucasian (> 50\% of patients) & NA & $4(20)$ \\
\hline Mix (all races $<50 \%$ of patients) & NA & $9(45)$ \\
\hline \multicolumn{3}{|l|}{ Physician practice: patient insurance coverage } \\
\hline $\begin{array}{l}\text { Physicians with commerically/privately insured (> 50\% } \\
\text { of patients) }\end{array}$ & NA & $11(55)$ \\
\hline Physicians with Medicare insured ( $>50 \%$ of patients) & NA & $1(5)$ \\
\hline $\begin{array}{l}\text { Physicians with mix (private and Govt insured, all }< \\
50 \% \text { of patients) }\end{array}$ & NA & $8(40)$ \\
\hline
\end{tabular}

CLE = cutaneous lupus erythematosus; NA = not applicable or data not available; SLE = systemic lupus erythematosus.

aPatient participants were recruited from a database of individuals who agreed to be contacted for research purposes. Interviews were conducted between November 2020 and January 2021 (patients) and between December 2020 and February 2021 (physicians). ${ }^{b}$ Includes 1 patient who was currently in school.

Includes on disability $(n=8)$, retired $(n=4)$, homemaker $(n=4)$, unemployed, looking for work $(n=1)$, and student $(n=1)$.

dIncludes both SLE and CLE $(n=3)$ and unknown/not sure $(n=3)$.

and physicians' perceptions on the treatment journey for underrepresented patients and identify barriers to quality care. Methods In-depth qualitative interviews were conducted with patients with lupus from underrepresented populations (Black/ AA, Latino/a, Native American, Asian/Pacific Islander) and 
physicians (dermatology or rheumatology). Quota sampling was used to recruit patients from racially and ethnically diverse backgrounds and physicians with varied medical practices. Patient and physician participants provided informed consent. Semi-structured interviews explored patients' experiences with the healthcare system and physicians' challenges when treating patients with lupus.

Results Interviews were conducted with 33 patients and 20 physicians. Age, region, education, employment status, and type/severity of lupus varied among patients, as did physicians' work experience and practice settings (table 1). Patients reported challenges at each step of their journey. Prior to diagnosis, patients entered the healthcare system often lacking awareness of lupus disease and reported feeling initially ignored, dismissed, or misdiagnosed, which delayed treatment and triggered mistrust of the healthcare system. Lack of trust was cited by patients as a reason to discontinue treatment, despite persistent symptoms. Some patients reported perceived challenges with access to branded medications due to insurance coverage or delays in prior authorization and were concerned about losing their job and insurance. Patients communicated that treatment access might be improved by establishing support systems for reliable disease information (advocacy groups, community support), increasing cultural sensitivity in physician practices, and enabling an efficient and transparent treatment initiation process. From the physician perspective, barriers to treatment access included delayed diagnoses, patient concerns over side effects and the need for lifelong treatment, communication challenges with patients with limited English proficiency (LEP), and medication costs. Physicians suggested addressing perceived barriers by providing better patient information resources, having a live translator present during visits for patients with LEP, and navigating accessibility to medications through patient assistance programs to ensure access to branded therapies when needed.

Conclusions Improving access to quality care for underrepresented patients is essential to reduce health disparities across racial/ethnic groups and build trust in the healthcare system. Increasing disease awareness among these diverse groups and physicians, establishing patient support networks, and improving patient-physician communication should be critical components of health equity efforts.

\section{REFERENCES}

1. Arora. Rheum Dis Clin N Am. 2020;46:623-638.

2. Maningding. Arthritis Care Res. 2020;72(5):622-629.

\section{IMPACT STUDY: CAN WE CONDUCT A TRIAL WITH A BIOLOGIC TO PREVENT PREECLAMPSIA IN WOMEN WITH ANTIPHOSPHOLIPID SYNDROME?}

'Jane E Salmon*, 'Marta Guerra, ${ }^{2}$ Mimi Kim, ${ }^{3} \mathrm{D}$ Ware Branch. ${ }^{1}$ Hospital for Special Surgery, USA; ${ }^{2}$ Albert Einstein College of Medicine, USA; ${ }^{3}$ University of Utah, USA

\subsection{6/lupus-2021-lupus21century.55}

Background Pregnant women with antiphospholipid antibodies and/or lupus have higher rates of adverse pregnancy outcomes (APOs), such as fetal loss and preterm birth due to severe preeclampsia (PE) or placental insufficiency (PI). The presence of lupus anticoagulant (LAC) is the strongest predictor of an APO. At present, there is no effective treatment for women with these high-risk pregnancies, but in an animal model that mimics this human condition we found that TNF- $\alpha$ was a critical downstream effector of abnormal placental development and fetal damage, and that TNF- $\alpha$ blockade normalized placentation and spiral artery remodeling, and rescued pregnancies. We sought to determine whether TNF- $\alpha$ blockade during pregnancy, added to a regimen of heparin and low dose aspirin, reduces the rate of APOs in women with clinical APS and LAC.

Methods The IMPACT Study (IMProve Pregnancy in APS with Certolizumab Therapy) is an open label single-stage Phase II trial to evaluate the effect of certolizumab, a TNF- $\alpha$ inhibitor that does not cross the placenta and has been shown to be well tolerated in pregnancy, to reduce the risk of adverse outcomes in this population. Patients with APS and LAC are referred to IMPACT by their physicians (often before a planned pregnancy), consented and screened remotely by a study investigator, and medication is sent to the patient. They are treated with certolizumab from gestational week 8 through 28. Investigators contact patients every 2 weeks and receive medical reports and research blood samples monthly. Without the intervention being studied, $44 \%$ of these pregnancies were predicted to have serious complications, including severe preterm preeclampsia, growth restricted fetuses, and/or fetal death. Assuming a target $50 \%$ reduction in APO rate with the intervention, forty-five evaluable pregnancies are required for $90 \%$ power to prove that the intervention reduces the rate of adverse outcomes.

Results Since May 2017, we have enrolled 33 patients from nine states. Characteristics: $61 \%$ had previous PE or PI $<34$ weeks requiring delivery, $70 \%$ had previous fetal death $>10$ weeks, $12 \%$ had neonatal death due to complications of prematurity; 42\% venous thrombosis, 24\% Stroke/TIA, 24\% SLE. There have been no study drop-outs.

Conclusion We are successfully using a 'rare disease study' approach to conduct the first trial of a biologic therapy to prevent pregnancy complications women with APS and LAC. For rare conditions such as this, one must target assorted specialists (maternal-fetal medicine, hematology, rheumatology) for recruitment. Identifying patients preconceptionally is ideal, because improving placental vascularization requires enrollment early in pregnancy, and screening evaluations take time. Despite regulatory and logistic complexities and the small number of patients meeting inclusion criteria, their enthusiasm and that of their physicians has allowed us to move forward, albeit slowly.

Acknowledgements NIAMS, Lupus Research institute, Lupus Foundation of America.

Trial Registrations ClinicalTrials.gov NCT03152058.

\section{PATIENT AND PHYSICIAN PERSPECTIVES OF LUPUS FLARE}

${ }^{1}$ Jennifer L Rogers*, ${ }^{1}$ Megan EB Clowse, ${ }^{2}$ Kevin McKenna, ${ }^{2}$ Summer Starling, ${ }^{2}$ Teresa Swezey, ${ }^{2}$ Nneka Molokwu, ${ }^{2}$ Amy Corneli, ${ }^{3}$ David S Pisetsky ${ }^{1}$ Kai Sun, ${ }^{1}$ Lisa G Criscione-Schreiber, ${ }^{1}$ Rebecca E Sadun, ${ }^{1}$ Mithunan Maheswaranthan, ${ }^{1} J a y a n t h$ Doss, ${ }^{1}$ Amanda M Eudy. 'Department of Medicine, Duke University Medical Center, USA; ${ }^{2}$ Department of Population Health Sciences, Duke University, USA; ${ }^{3}$ Durham VA Medical Center, Duke University Medical Center, USA

\subsection{6/lupus-2021-lupus21 century.56}

Background Lupus flares can be associated with increased damage, poor outcomes and decreased health-related quality of life. Patients and providers may differ about the nature of a flare, however, complicating communication and 